\title{
Polarized light pollution of matte solar panels: Anti-reflective photovoltaics reduce polarized light pollution but benefit only some aquatic insects
}

\author{
Dénes Száz ${ }^{1}$, Dávid Mihályi ${ }^{1}$, Alexandra Farkas ${ }^{1,2}$, Ádám Egri ${ }^{1,2}$, András Barta ${ }^{1,3}$, \\ György Kriska ${ }^{2,4}$, Bruce Robertson ${ }^{5}$ and Gábor Horváth ${ }^{1, *}$ \\ 1: Environmental Optics Laboratory, Department of Biological Physics, Physical Institute, \\ Eötvös University, H-1117 Budapest, Pázmány sétány 1, Hungary \\ 2: Danube Research Institute, MTA Centre for Ecological Research, \\ H-1113 Budapest, Karolina út 29-31, Hungary \\ 3: Estrato Research and Development Ltd., H-1121 Budapest, Mártonlak utca 13, Hungary \\ 4: Group for Methodology in Biology Teaching, Biological Institute, Eötvös University, \\ H-1117 Budapest, Pázmány sétány 1, Hungary \\ 5: Division of Science, Mathematics and Computing, Bard College, 30 Campus Drive, \\ Annandale-on-Hudson, New York 23504, USA \\ *corresponding author, e-mail address: gh@arago.elte.hu
}

Running title: Polarized light pollution of matte solar panels

\section{Changes performed on the basis of the comments of Referee 1 Changes performed on the basis of the comments of Referee 2 Changes performed on the basis of the comments of the Editor}

\begin{abstract}
Photovoltaic solar panels represent one of the most promising renewable energy sources, but are strong reflectors of horizontally polarized light. Polarized light pollution (PLP) associated with solar panels causes aquatic insects to prefer to oviposit on panels over natural water bodies, with potential to negatively impact their global populations as solar energy expands. We evaluate the hypothesis that anti-reflective coatings (ARC) used to increase the energy efficiency of solar panels will reduce the amount of PLP they reflect, and their attractiveness to aquatic insects. We created artificial test surfaces that mimicked the optical properties of coated and uncoated solar panels and exposed them to wild populations of polarotactic mayflies (Ephemeroptera), horseflies (Tabanidae) and non-biting midges (Chironomidae) used as indicators of PLP. We evaluated the reflection-polarization properties of test surfaces from four different angles of view and under sunny and overcast skies in the visible and ultraviolet parts of the spectrum. Matte (i.e. ARC-coated) sunlit solar panels were strong sources of horizontally polarized light only when the sun was afront and behind, in contrast to uncoated panels which exceeded common polarization-sensitivity thresholds for aquatic insects from all four viewing directions. As predicted by these sunlight PLP patterns, horsefly numbers and water-seeking behaviors were significantly reduced by ARCs. Under overcast skies, both matte and shiny (i.e.
\end{abstract}


uncoated) panels were insect-detectible sources of PLP. Matteness modestly reduced the degree of polarization of reflected light, but not sufficiently such that fewer chrionomids were attracted to them. Mayflies actually preferred matte panels under overcast skies. ARCs are most likely to reduce PLP and benefit aquatic insects under sunny skies and when used in conjunction with white non-polarizing gridding, but may actually exacerbate the severity of their negative effects under overcast conditions. Consequently, even current ARC technology has a role to play in aquatic insect conservation, but strategic deployment of solar panels away from water bodies and temperate regions may trump these benefits.

Keywords: aquatic insect, mayfly, chironomid, horsefly, anti-reflective coating, photovoltaics, polarization, solar panel, polarized light pollution, polarotaxis, polarization vision, visual ecology

\section{Introduction}

Photovoltaic (PV) electricity generation is the most rapidly growing portion of the energy sector with growth in installed capacity rates ranging from 34 to $82 \%$ in North America, Europe and Australia over the past decade (EPIA 2012). Declining manufacturing costs and rapid technological innovation have led the International Energy Agency to predict that PV deployment will be twice as high by 2020 (IEA 2014). Solar panels and batteries have expanded globally as a result of improved performance and lower cost such that many communities, villages and individual households in the developing world can afford them (Alstone et al. 2015). Although solar expansion would benefit the integrity of the ecosphere by reducing global greenhouse gas emissions, it may also lead to unintended ecological impacts.

Photovoltaic solar panels are strong sources of a form of photopollution known as polarized light pollution (PLP, Horváth et al. 2009, 2010a). Horizontally polarized light is a fundamentally important visual cue used by most taxa of flying aquatic insects (e.g. mayflies: Ephemeroptera) to locate bodies of water in which they can lay their eggs (Schwind 1991, 1995; Horváth \& Varjú 2004). Water is, by far, the strongest and most ubiquitous source of naturally-occurring horizontally polarized light (Horváth \& Varjú 2004), but shiny black man-made objects such as windows, asphalt roads and solar cells (Kriska et al. 1998; Horváth et al. 2008, 2010a) can polarize light even more strongly than water. Such artificial polarizers are so attractive to aquatic insects that they actually prefer to lay their eggs on these surfaces where they perish, even when suitable water bodies are available (Kriska et al. 1998; Horváth et al. 2010a).

As strong sources of PLP, artificial polarizers like solar cells are examples of evolutionary traps: scenarios in which, due to some rapid change in the environment, animals are suddenly triggered to prefer dangerous behaviors over safer ones (Schlaepfer et al. 2002; Horváth et al. 2010a). And because evolutionary traps can lead to rapid population declines and even population extirpation (Kokko \& Sutherland 2001; Fletcher et al. 2012), there is concern that rapid expansions of PV may lead to declines in aquatic insects and the species that prey on them (e.g. fish, Horváth et al. 2009; Robertson et al. 2013). Solar installations in the U. S. state of California may kill up to 28000 birds per year (Kagan et al. 2014), and because certain birds are capable of sensing linearly polarized skylight and using this information to navigate (Horváth \& Varjú 2004; Muheim 2011; Horváth 2014), it is possible that they may also be attracted to PV installations, because they mimic the appearance of water bodies or concentrate insect prey (Horváth et al. 2009; Walston et al. 2015).

Former research has found that the introduction of unpolarizing white grid lines on solar panels is effective in rendering panels unattractive to many taxa of aquatic insects, though these lines reduce solar-active areas and energy capture by about 1\% (Horváth et al. 2010a). More recently, we have seen the invention of anti-reflective coatings (ARCs) that can improve efficiency up to $37 \%$ (Ali et al. 
2014). These clear panel coatings use microscopic protrusions (e.g. pyramids: Campbell \& Green 1987, or carbon nanotubes: Kuo et al. 2008; Kang et al. 2009) or air bubbles (Kim 2007) to make the surface of the glass/plastic layer porous (Fig. 1) and trap incoming light that would otherwise reflect off the surface (Kuo et al. 2008). Because they reduce reflected light, we suspect that ARC solar cells may have another advantage: a reduction in the PLP they produce.

To test this hypothesis, we used test surfaces identical to the glass panes used in ARC (matte) and uncoated (shiny) solar panels and measured their optical properties to visualize the angle and degree of polarization of reflected light in the visible and ultraviolet parts of the spectrum under a range of outdoor lighting conditions. We predict that both coated and uncoated panels will linearly polarize reflected sunlight and skylight, but that the fraction of reflected light that is horizontally polarized will be reduced by anti-reflective coating. Next, we tested the attractiveness of these test surfaces to flying polarotactic horseflies (Tabanidae), mayflies (Ephemeroptera) and non-biting midges (Chironomidae), common aquatic insects likely to encounter PV panels. Although aquatic insects in general and the groups studied here usually do not need conservation measures, many species of mayflies and dragonflies, for example, are endangered and highly protected in several countries. Due to the health risk caused by their blood sucking from livestock and humans, the number of parasitic horseflies should be reduced by different traps (Blahó et al. 2012a; Egri et al. 2013; Krcmar 2013; Herczeg et al. 2014). The polarotactic aquatic insect species studied in this work are used simply as indicators of PLP. Furthermore, they were selected, because they were the most abundant polarotactic aquatic arthropod taxa at our study sites and because their taxonomic diversity allow us to ask whether responses to ARCs will be taxon dependent. Because a reduced fraction of horizontally polarized light is associated with reduced attractiveness to polarotactic arthropods in general (Horváth 2014), we predict that the insect taxa in our study will find matte panels less attractive.

\section{Materials and methods}

\section{Test surfaces}

We created two kinds of test surfaces that we exposed to wild flying aquatic insects: shiny (smooth) black, and matte (rough) black. Each test surface was composed of two glass panes (smooth window glass, $400 \mathrm{~mm} \times 400 \mathrm{~mm} \times 3 \mathrm{~mm}$ ) underlain with black cardboard which collectively mimics the polarization-relevant optical properties of solar panels. The matte test surface consisted of a pane of glass with anti-reflective porous upper and lower surfaces manufactured by the Danish firm, Sunarc Technology for use in the solar industry (http://www.sunarc.net/index.php/ap-processing/argenerelt). This surface accomplishes anti-reflection via a random array of microscopic glass spheres interspersed with air bubbles (Fig. 1). Glass panes were held in place with their respective black bases using a 20 $\mathrm{mm}$ thick, shiny black wooden frame. A given test surface $(440 \mathrm{~mm} \times 880 \mathrm{~mm})$ consisted of a pair of quadratic $(400 \mathrm{~mm} \times 400 \mathrm{~mm})$ wooden-framed glass surface of the same kind (shiny or matte) that were placed on the ground next to each other without gap. The matte and shiny test surfaces were placed along a straight line $50 \mathrm{~cm}$ apart from each other. We chose to construct our own simulated matte and shiny solar test panels rather than purchasing them in order to ensure that they differed only in their surface roughness with the same dimensions, shape, frame and absorbion layer (the darkcolored backing substrate).

\section{Field experiment 1: horseflies}

The shiny test surfaces in this study have nearly identical reflection-polarization characteristics as real solar panels with a shiny (smooth) black surface (Horváth et al. 2010a). The black cardboard underneath the glass acts to maximize light absorption. In previous field experiements with horseflies 
and mayflies, the attractiveness of different polarizing visual targets was studied by covering the test surfaces with adhesive designed to trap insects touching down on the test surface (Horváth \& Varjú 2004; Kriska et al. 2009; Blahó et al. 2013; Herczeg et al. 2015; Horváth 2014). The advantage of this method is that the number of insects landing on the surfaces can be accurately estimated simply by counting captures. However, the adhesive increases reflectivity of the matte/rough surfaces, which would make them more polarized and jeopardize the study.

The goal of this experiment was to test the relative attractiveness of test surfaces to horseflies known to be more attracted to stronger sources of horizontally polarized light (Horváth et al. 2008; Krcmar 2013). We performed the experiment over 11 days between 5 July and 1 August 2014 under warm, sunny conditions on a Hungarian horse farm in Szokolya $\left(47^{\circ} 52^{\prime} \mathrm{N}, 19^{\circ} 00^{\prime} \mathrm{E}\right.$ ), where horseflies are abundant (Kriska et al. 2009; Blahó et al. 2012a,b; Egri et al. 2012a,b, 2013). Test surfaces were placed on the ground in a meadow $50 \mathrm{~cm}$ apart, $5 \mathrm{~m}$ from a row of trees and bushes. Two observers sat $2 \mathrm{~m}$ from the test surfaces to record behavioral data. The experiment began in the morning and stopped in the afternoon and the two test surfaces were swapped every 30 minutes to eliminate site-specific bias in catches. The exposure time (1.5-6.0 h), onset (9:30-12:30 $\mathrm{h}=$ Greenwich Mean Time $+2 \mathrm{~h}$ ) and conclusion (12:30-17:00 h) were adjusted to avoid rapid temperature drops and precipitation because horseflies are only active in warm and sufficiently calm weather. We combined all of the observations from different days into a single statistical analysis.

The following three horsefly reactions were registered: (1) Aerial looping in any (horizontal, tilted or vertical) plane (a flying horsefly approached the test surface and performed at least one loop in the air above it within a few decimeters). (2) Touch-down (a horsefly touched the test surface at least once, then flew away within 3 seconds). (3) Landing (a horsefly landed on the test surface and remained on it at least for 3 seconds). Eggs were not laid. Reactions 1 and 2 are typical to horseflies inspecting and touching the water surface during drinking or bathing, while behavior 3 represents investigation of a suitable oviposition site or blood source (Horváth et al. 2008; Krcmar \& Lajos 2011; Blahó et al. 2014). Observers had extensive field experience in visually identifying horseflies and identified insects to the family level. Previous field experiments using polarizing test surfaces performed at the same site (Blahó et al. 2014; Herczeg et al. 2014) found the following horsefly species: Tabanus tergestinus, T. bromius, T. bovinus, T. autumnalis, Atylotus fulvus, A. loewianus, A. rusticus, Haematopota italica.

Observers counted reaction groups (how many times a horsefly individual reacted to a given test surface with aerial looping, touch-down, or landing, excluding repetitions by the same individual before flying away) and reaction items (how many times a given reaction element - looping, touching, landing - was performed by a given horsefly, including repetitions by the same individual before flying away). For example, if 4 horseflies reacted with aerial looping and each horsefly performed 3 loops above a test surface, then reaction groups $=4$, and reaction items $=4 \times 3=12$. The advantage of the parallel recording of reaction groups and reaction items is that both variable are good measures of attractiveness: the former characterizes the frequency of the different behavior types (looping, touching, landing), while the latter gives the intensity of these types. According to our earlier similar field experiments with horseflies, the investigated horsefly behaviors 1,2 and 3 are reliable indicators of attraction, regardless of abundance, because we know from previous studies (Horváth et al. 2010a,b; Blahó et al. 2014; Herczeg et al. 2014, 2015) that the numbers of reaction groups and items are positively correlated with abundance.

\section{Field experiment 2: mayflies and non-biting midges}

The goal of this experiment was to test the relative attractiveness of test surfaces to mayflies and nonbiting midges. Experiment 2 was conducted between 4 and 30 May 2015 on 8 warm days in the Hungarian Duna-Ipoly National Park at Dömörkapu $\left(47^{\circ} 40^{\prime} \mathrm{N}, 19^{\circ} 03^{\prime} \mathrm{E}\right)$, where an asphalt road runs 
in the immediate vicinity (within a few metres) of a mountain creek, from which several emphemeroptera (Baetidae, Heptageniidae) and chironomid species known to be attracted to horizontally polarized light (Kriska et al. 1998, 2007, 2009; Horváth et al. 2010a, 2011) emerge and swarm above the road at dusk in every May and July.

The two (matte and shiny) horizontal black test surfaces were laid on the asphalt road in a

Although horseflies, mayflies and non-biting midges have green-, blue- and UV-sensitive photoreceptors (Briscoe \& Chittka 2001), the spectral range in which they perceive polarization is still not known. We measured the reflection-polarization characteristics of our test surfaces from different directions of view relative to the solar meridian under sunlit and shady conditions, because patterns depend on the illumination circumstances and the viewing direction, and flying insects can approch solar panels from different directions. The patterns of the degree $d$ and angle $\alpha$ of linear polarization of light reflected from the matte (rough) and shiny (smooth) test surfaces used in our field experiments 1 and 2 were measured by imaging polarimetry in the red $(650 \mathrm{~nm})$, green $(550)$, blue $(450 \mathrm{~nm})$ and ultraviolet $(350 \mathrm{~nm})$ spectral ranges. In the visible range, we measured with a common imaging polarimeter, the hardware and software of which have been described elsewhere (Horváth \& Varjú (1997, 2004). In the ultraviolet (UV) range (using the same software as in the visible one), we used an UV-sensitive polarimeter composed of an UV-transmitting linearly polarizing filter (HNP'B), an UVtransmitting lens with a focal length of $60 \mathrm{~mm}$ (Jenoptik CoastalOpt UV-VIS-IR) and an UV-sensitive camera (Nikon D7100 UV mod). In the polarization patterns, both $d$ and $\alpha$ of reflected light change within the area of a given test surface due to the change of the angle of reflection and to the change of the optical variables (intensity, degree and angle of polarization) of incoming sky- and sunlight. To characterize the polarizing capability of a given test surface, we computed the mean and standard deviation of $d$ and $\alpha$ averaged on its surface area. In this work we show only the polarization patterns of the test surfaces measured in the green and UV spectral range, since the patterns were very similar in the red and blue parts of the spectrum. Polarotactic aquatic insects identify an object as a water body when the object-reflected light exhibits the following characteristics: 1) $d>d^{*}$ and 2) angles $\left|\alpha-90^{\circ}\right|<$ $\alpha^{*}$ (Horváth 2014). In this work we used the threshold values $d^{*}=15 \%$ and $\alpha^{*}=10^{\circ}$ being typical for horseflies and mayflies (Kriska et al. 2009). However, using other threshold values, our conclusions would not change. 


\section{Statistical analyses}

Since the distribution of our count data was non-normal (like most count data, our data were distributed in a Poisson fashion), we used non-parametric Mann-Whitney U test (Zar 2010) to compare differences between the attractiveness of matte (rough) and shiny (smooth) test surfaces to polarotactic horseflies, mayflies and non-biting midges in our field experiments. We performed also a Wilcoxon matched pair test and obtained the same results as for the non-parametric Mann-Whitney U test. Because the goal of this study was to examine the relative conservation-benefit of anti-reflective solar panel coatings for insects, we were interested in consistent effects of this treatment over time and not day-to-day variation in responses that could be influenced by fine scale variation in environmental or ecological conditions. Prior to analysis, we pooled captures from all sampling sessions of experiments 1 and 2. Instead of spatial replication, we replicated our experiment through time, because we were interested in testing for overall trends of species-specific polarized light pollution of matte and shiny solar panels. Note that we used only one test surface of each treatment (matte versus shiny). The two panels of the same given type (matte, shiny) are not independent replicates, thus their captures were pooled. All statistical tests were performed with the use of the software Statistica 8.0 (Zar 2010).

\section{Results}

\section{Attractiveness of test surfaces to aquatic insects}

During the 11-day-long experiment, we observed 2925 looping behaviors and 3579 touch-downs executed by 672 and 717 individual horseflies, respectively. This included 812 landings lasting over 7.1 hours in total. Over the 8 days in which we recorded responses of mayflies and non-biting midges to test surfaces, we observed a total of 367 mayflies and 1075 midges in the experiment. Note, however, that we cannot be sure that there were no returning individuals. Thus, pseudo-replication was an issue, as the insects were not captured, but this was appropriately handled by pooling the data for all sampling sessions. Horseflies executed more habitat- and oviposition-related behaviors in association with the shiny test surface. For reaction groups looping, touching and landing, the shiny black test surface was 3.4, 5.6 and 5.2 times more attractive to horseflies, respectively, than the matte black test surface (Fig. 2, Supporting Fig. S1). For reaction items of looping, touching and landing, the shiny black test surface was 4.4, 7.5 and 7.2 times more attractive to horseflies, respectively, than the matte black one (Fig. 2). In contrast, the matte black test surface was 4.0 times more attractive to mayflies, than the shiny black one, but non-biting midges found both experimental surfaces equally attractive (Fig. 3., Supporting Fig. $\mathrm{S} 2)$

\section{Reflection-polarization characteristics of test surfaces under clear skies}

In Fig. 4, polarization data are presented for all three (red, green, blue) parts of the spectrum. When facing the sun, the $d$ of light reflected from the matte black test surface is about $10 \%$ higher than that from the shiny black test surface (e.g. $d_{\text {shiny }}=70.9 \pm 8.9 \%$ and $d_{\text {matte }}=80.8 \pm 7.2 \%$ in the blue spectral range, Figs. 4, 6 and 7, Supporting Table S1). The standard deviation of $\alpha$ of light reflected from the matte black test surface is about twice as large as that from the shiny test surface (e.g. $\alpha_{\text {shiny }}=86.4 \pm$ $3.6^{\circ}$ and $\alpha_{\text {matte }}=84.4 \pm 7.5^{\circ}$ in the blue spectral range). Due to these reflection-polarization characteristics, the area detected polarotactically as water is much smaller for the sunlit matte black test surface than for the sunlit shiny black one, which predicts that in sunshine the former is less attractive to polarotactic insects than the latter.

Looking perpendicular to the solar-antisolar meridian, when the sun shines from the left or right, the shiny black test surface reflects light with lower degrees of polarization (blue: $d_{\text {shiny }}=21.6 \pm$ 
$7.2 \%$, green: $d_{\text {shiny }}=17.1 \pm 6.1 \%$, Fig. 6 ) than the matte black test surface (blue: $d_{\text {matte }}=22.1 \pm 6.1 \%$, green: $d_{\text {matte }}=20.2 \pm 5.9 \%$, Figs. 4 and 7, Supporting Table S1). From this direction of view, the direction of polarization of light reflected from the matte test surface deviates from the horizontal so much that the matte surface is polarotactically not sensed as water. On the other hand, from this viewing direction, the shiny black test surface reflects nearly horizontally polarized light, independently of the spectral range. Due to these reflection-polarization characteristics in sunshine, from this direction of view a considerably large area of the sunlit shiny black test surface is expected to be more attractive to aquatic insects in all three (red, green, blue) spectral ranges, while neither part of the sunlit matte black test surface is sensed as water.

When the sun shines from behind, the direction of polarization of light reflected from both the shiny and matte black test surfaces is approximately horizontal in all three (red, green, blue) spectral ranges. The degree of polarization of light reflected from the matte test surface is slightly lower (e.g. $d_{\text {matte }}=36.9 \pm 7.9 \%$ in the blue) than that from the shiny one (blue: $d_{\text {shiny }}=51.1 \pm 4.4 \%$ ). Thus, in sunshine from this viewing direction, the sunlit shiny black test surface is expected to be more attractive to polarotactic insects than the sunlit matte black one, again Figs. 4, 6, 7 and 8, Supporting Table S1). Independently of the viewing direction from the sun, the sunlit shiny black horizontal test surface is predicted to be more attractive to polarotactic insects than the sunlit matte black one, because larger portions of the shiny surface are sensed polarotactically as water than for the matte one.

Similar reflection-polarization characteristics occurred for the sunlit shiny and matte test surfaces in the UV (350 nm) part of the spectrum (Fig. 5, Supporting Figs. S3 and S4, Supporting Table $\mathrm{S} 2)$.

\section{Reflection-polarization characteristics of test surfaces under overcast skies}

Under overcast skies, both the shiny and the matte black test surfaces reflect horizontally $\left(\alpha \approx 90^{\circ}\right)$ polarized light in the visible part of the spectrum, independently of the direction of view relative to the invisible sun (Figs. 4 and 8). Under overcast (or shady) conditions, the standard deviation of the horizontal direction of polarization of light reflected from the matte black test surface is smaller (green: $6.6^{\circ} \leq\left|\Delta \alpha_{\text {matte }}\right| \leq 7.7^{\circ}$ ) than that from the shiny black one (green: $7.1^{\circ} \leq\left|\Delta \alpha_{\text {shiny }}\right| \leq 8.0^{\circ}$ ). On the other hand, our shiny black test surfaces reflect light with higher degrees of polarization (green: $d_{\text {shiny }}=50.1$ $59.9 \pm 8.9-11.9 \%$ ) than the matte black ones (green: $d_{\text {matte }}=38.3-52.3 \pm 5.3-7.8 \%$, Figs. 4 and 8). Under overcast sky conditions, similar reflection-polarization characteristics of the shiny and matte test surfaces occurred in the UV (350 nm) spectral range (Fig. 5, Supporting Fig. S5, Supporting Table S2).

\section{Discussion}

In this work polarized light pollution of solar panels is quantified with their attractiveness to positively polarotactic mayflies (Ephemeroptera), horseflies (Tabanidae) and non-biting midges (Chironomidae). The measure of attractiveness is the number of reactions (looping, touching, landing) of horseflies, and the abundance of mayflies and non-biting midges on or just above the test surfaces. Depending on the sky condition (clear or cloudy) and the direction of reflection, each of the three aquatic insect groups we tested exhibited a categorically different response to anti-reflective coatings on solar panels. Horseflies experienced a reduced attraction to matte (ARC-coated) panels, midges exhibited no measurable response and, in opposition to our predictions, mayflies actually preferred to associate with matte panels.

Natural water bodies vary widely in the degree to which they polarize reflected sunlight, typically polarizing with $d=15-80 \%$. We found (Figs. 4, 6 and 7) that sunlit horizontal matte black solar panels reflect horizontally polarized light, and thus can be attractive $(d>15 \%)$ to water-seeking polarotactic insects, only from two directions of view: when the sun is afront and behind. From all 
other viewing directions sunlit horizontal matte solar panels reflect non-horizontally polarized light which is unattractive to aquatic insects. In contrast, horizontal shiny black solar panels reflected horizontally polarized light with $d>15 \%$ from all angles of view (Figs. 4, 6 and 7). By consistently horizontally polarizing light from more directions, shiny (uncoated) solar panels should be more important sources of polarized light pollution that maladaptively attract more aquatic insects to them. Indeed, these reflection-polarization characteristics were good predictors of horsefly responses to shiny and matte test surfaces, especially given that the test panels were usually sunlit during experiments, and horseflies did not fly and react to our test surfaces under overcast skies. Blahó et al. (2014) observed similar reactions of polarotactic horseflies to matt black car surfaces.

In experiment 2 the panel illumination situation was quite different, and test surfaces were in the shade of the surrounding trees and bushes. These lighting conditions are similar to those measured under an overcast sky (Figs. 4 and 8). Yet, in contrast to previous research showing that mayflies are more attracted to surfaces reflecting a consistantly higher degree of horizontally polarized light (Kriska et al. 1998, 2009; Horváth et al. 2010a, 2011; Blahó et al. 2014), mayflies in our study actually preferred the matte test surface that reflected light with approximately $10 \%$ less degree of polarization. Both the matte and shiny black test surfaces reflected horizontally polarized light, but the standard deviation $\Delta \alpha_{\text {matte }}$ of the angle of polarization $\alpha_{\text {matte }}$ of light reflected from the matte solar panels was slightly smaller than $\Delta \alpha_{\text {shiny }}$ from the shiny ones. Blahó et al. (2014) found a similar result when they noted that cars with a matte dark grey car finish and smaller $\Delta \alpha$ were much more attractive to the same mayfly species than a shiny black finish with larger $\Delta \alpha$. These optical characteristics indicate calmer, more still bodies of water (Fig. 3, Supporting Fig. S2, Encalada \& Peckarsky 2007).

The angle $\alpha$ of polarization of water-reflected light depends strongly on the angle of reflection. If the tilt of a reflecting surface changes periodically, the angle of reflection changes also periodically, the consequence of which is the periodical temporal change $\Delta \alpha$ of $\alpha$ of reflected light. If the reflector is a water surface, its undulation causes such $\Delta \alpha$ variations: the stronger the undulation, the rougher is the water surface, and the larger is $\Delta \alpha$. Calmer waters have a smoother surface characterized by smaller $\Delta \alpha$. Thus, water-seeking flying polarotactic mayflies could sense remotely the surface roughness and thus the calmness/turbulence of water bodies on the basis of the standard deviation $\Delta \alpha$ of polarized reflected light. Certain mayflies may prefer calmer water bodies, because their larvae can develop only in such waters, since, for example, due to their weaker musculature the larvea are easily drifted by moving, turbulent water, the surface of which is rougher (e.g., Encalada \& Peckarsky 2007).

Non-biting midges (chironomids) were attracted equally to both matte and shiny solar panels (Fig. 3, Supporting Fig. S2). It may be that chironomids are insensitive to the rather modest reductions in the degree of polarization $d$ of reflected light accomplished by anti-reflective coating. Indeed, thresholds of $d$ necessary for polarization detection vary amongst taxa (Horváth \& Varjú 2004), as do behavioral reaction norms mapping the degree to which attraction varies with $d$ (Kriska et al. 2009). Certainly, the fact that other experiments have demonstrated that at the attractiveness of a polarized light source to midges increases with its $d$ over a greater range of percent polarization (Kriska et al. 1998, 2007, 2009; Horváth et al. 2010a, 2011) suggest that ARC's were not sufficiently effective to reduce chironomid attraction.

Our experiment 2 with mayflies and non-biting midges was performed at an asphalt road above which these insects swarmed due to the horizontally polarized asphalt-reflected light which attracted them to the road. These polarotactic insects emerged from a mountain creek running parallel to the road at a few metres distance. Earlier, similar choice experiments have been conducted with these species, the behavior of which over the asphalt road and various test surfaces laid on the road as well as above the surface of the nearby creek is described in detail elsewhere (Kriska et al. 1998; Horváth et al. 2010c, 2011). The reflection-polarization characteristics of this asphalt road and the different test surfaces laid onto it have also been measured (Kriska et al. 1998; Horváth et al. 2010c, 2011). In experiment 2 the weakly (relative to our test panels) horizontally polarizing asphalt road functioned as 
an initial attractor of the investigated insects to the study site.

Collectively, our results show that currently available anti-reflective coatings can provide some solution to eliminating ecological traps created by solar panels. However, PLP reduction is rather modest and only sufficient to benefit some taxa and under particular weather conditions. Mayfly preference for matte panels is concerning in that their optical properties seem to reinforce the strength of an existing ecological trap caused by solar panels. However, our results and previous work suggest this will only occur under overcast skies and will therefore be more problematic in wetter, more temperate zones. Moreover, vertical artificial polarizers are just as effective at triggering maladaptive behavior as horizontal ones (Kriska et al. 2008) and so the orientation of panels at angles perpendicular to the direction of the mid-day sun is not likely to either mitigate or exacerbate the patterns we have seen here. Previous research has shown that one solution to this problem is to manufacture PV panels with a dense grid of thin white lines (Horváth et al. 2010a). Zebras, for example, use the same trick (i.e. have a black-and-white stripe pattern) to keep their coat unattractive to polarotactic blood-sucking female horseflies (Egri et al. 2012b; Blahó et al. 2013). Our results suggest that anti-reflective coatings may also play a role in mitigating the ecological impacts of PV expansion on polarotactic animals, and can work in tandem with gridding.

Because polarized light pollution triggers severely maladaptive behavior in nearly every single species of aquatic insect ever tested (but see Bernáth et al. 2012), the increasing popularity and affordability of PV panels and the projected global expansion have potentially lead to a corresponding impact on local insect populations, especially where they occur near larger water bodies (rivers and lakes) and wetlands. Even so, it is not currently known whether there is within-population variation in behavioral responses to polarized light such that only a fraction of the population are impacted by these ecological traps. Also lacking is empirical evidence that polarized light pollution, or ecological traps in general, have led to population declines in wild animal populations.

Because our results show that matte coatings do not consistently mitigate polarized-light-driven ecological traps associated with solar panels, and actually make them worse for at least one family of insects (Ephemeroptera), it is not clear that they can play a central role in insect conservation. Even so, our experiments were conducted in a relatively mesic ecosystem. Insect species that have evolved in more xeric, less-often overcast systems like deserts in which large-scale photovoltaic installations are placed may have more consistent and positive responses to matte (anti-reflective) coatings, but more research is needed to examine how a broader array of aquatic arthropod taxa respond to similar reductions in PLP. Because white, non-polarizing gridding on solar panels are known to reduce the attractiveness of artificial polarizers to aquatic insects (Horváth et al. 2010a), future research should identify the minimum density and width of stipping necessary to maintain this effect so as to maxmimize solar panel efficiency. If the reduced attractiveness associated with gridding and that associated with reduced PLP due to ARCs are additive, these tools may be effectively deployed in tandem. At present, however, the most effective conservation measure may be locating solar panels and other artificial polarizers away from riparian corridors that act as centers of aquatic insect activity and dispersal.

Acknowledgments: This work was supported by the grant NKFIH PD-115451 (Studying the polarotaxis of aquatic arthropods and complex optical ecological traps in the aspect of conservation biology) received by Ádám Egri from the Hungarian National Research, Development and Innovation Office. Many thanks to Csaba Viski (Szokolya, Hungary), who allowed our experiments on his horse farm. We are grateful to the Danish firm, Sunarc Technology, which provided us with the matte glass panes used in anti-reflective photovoltaic solar cells. We are grateful to Miklós Blahó for his assistance in the field experiment in Szokolya. The authors have no conflict of interest to declare. We are grateful to two anonymous reviewers for their constructive and positive comments. 


\section{References}

Ali K, Khan SA, Jafri MZM (2014) Effect of double layer $\left(\mathrm{SiO}_{2} / \mathrm{TiO}_{2}\right)$ anti-reflective coating on silicon solar cells. Int J Electrochem Soc 9:7865-7874

Alstone P, Gershenson D, Kammen DM (2015) Decentralized energy systems for clean electricity access. Nature Climate Change 5:305-314

Bernáth B, Horváth G, Meyer-Rochow VB (2012) Polarotaxis in egg-laying yellow fever mosquitoes Aedes (Stegomyia) aegypti is masked due to infochemicals. J Insect Physiol 58:1000-1006

Blahó M, Egri Á, Barta A, Antoni G, Kriska G, Horváth G (2012a) How can horseflies be captured by solar panels? A new concept of tabanid traps using light polarization and electricity produced by photovoltaics. Veter Parasitol 189:353-365

Blahó M, Egri Á, Báhidszki L, Kriska G, Hegedüs R, Åkesson S, Horváth G (2012b) Spottier targets are less attractive to tabanid flies: on the tabanid-repellency of spotty fur patterns. PLoS ONE 7(8): e41138 (doi:10.1371/journal.pone.0041138)

Blahó M, Egri Á, Száz D, Kriska G, Åkesson S, Horváth G (2013) Stripes disrupt odour attractiveness to biting horseflies: Battle between ammonia, $\mathrm{CO}_{2}$, and colour pattern for dominance in the sensory systems of host-seeking tabanids. Physiol Behav 119:168-174

Blahó M, Herczeg T, Kriska G, Egri Á, Száz D, Farkas A, Tarjányi N, Czinke L, Barta B, Horváth G (2014) Unexpected attraction of polarotactic water-leaving insects to matt black car surfaces: mattness of paintwork cannot eliminate the polarized light pollution of black cars. PLoS ONE 9(7): e103339 (doi: 10.1371/journal.pone.0103339)

Briscoe AD, Chittka L (2001) The evolution of color vision in insects. Ann Rev Entomol 46:471-510

Campbell P, Green MA (1987) Light trapping properties of pyramidally textured surfaces. J Appl Phys 62:243-249

Egri Á, Blahó M, Sándor A, Kriska G, Gyurkovszky M, Farkas R, Horváth G (2012a) New kind of polarotaxis governed by degree of polarization: attraction of tabanid flies to differently polarizing host animals and water surfaces. Naturwissenschaften 99:407-416

Egri Á, Blahó M, Kriska G, Farkas R, Gyurkovszky M, Åkesson S, Horváth G (2012b) Polarotactic tabanids find striped patterns with brightness and/or polarization modulation least attractive: an advantage of zebra stripes. J Exp Biol 215:736-745

Egri Á, Blahó M, Száz D, Barta A, Kriska G, Antoni G, Horváth G (2013) A new tabanid trap applying a modified concept of the old flypaper: Linearly polarising sticky black surfaces as an effective tool to catch polarotactic horseflies. Int J Parasitol 43:555-563

Encalada AC, Peckarsky BL (2007) A comparative study of the cost of alternative mayfly oviposition behaviors. Behav Ecol Sociobiol 61:1437-1448

EPIA (2012) Connecting the Sun: Solar photovoltaics on the road to large-scale grid integration. European Photovoltaic Industry Association, Brussells, Belgium. Available online: http://www.epia.org/news/publications/ (Retrieved 7 July 2015)

Fletcher RJ, Orrock JL, Robertson BA (2012) How the type of anthropogenic change alters the consequences of ecological traps. Proc Roy Soc B 279:2546-2552

Herczeg T, Blahó M, Száz D, Kriska G, Gyurkovszky M, Farkas R, Horváth G (2014) Seasonality and daily activity of male and female tabanid flies monitored in a Hungarian hill-country pasture by 
new polarization traps and traditional canopy traps. Parasitol Res 113:4251-4260

Herczeg T, Száz D, Blahó M, Barta A, Gyurkovszky M, Farkas R, Horváth G (2015) The effect of weather variables on the flight activity of horseflies (Diptera: Tabanidae) in the continental climate of Hungary. Parasitol Res 114:1087-1097

Horváth G (ed) (2014) Polarized Light and Polarization Vision in Animal Sciences (2nd ed.) Springer Series in Vision Research, vol. 2 (series eds: S. P. Collin, J. N. Marshall) Springer, Heidelberg, Berlin, New York

Horváth G, Varjú D (1997) Polarization pattern of freshwater habitats recorded by video polarimetry in red, green and blue spectral ranges and its relevance for water detection by aquatic insects. J Exp Biol 200:1155-1163

Horváth G, Varjú D (2004) Polarized Light in Animal Vision - Polarization Patterns in Nature; Springer, Heidelberg, Berlin, New York

Horváth G, Majer J, Horváth L, Szivák I, Kriska G (2008) Ventral polarization vision in tabanids: horseflies and deerflies (Diptera: Tabanidae) are attracted to horizontally polarized light. Naturwissenschaften 95:1093-1100

Horváth G, Kriska G, Malik P, Robertson B (2009) Polarized light pollution: A new kind of ecological photopollution. Front Ecol Environ 7:317-325

Horváth G, Blahó M, Egri Á, Kriska G, Seres I, Robertson B (2010a) Reducing the maladaptive attractiveness of solar panels to polarotactic insects. Cons Biol 24:1644-1653

Horváth G, Blahó M, Kriska G, Hegedüs R, Gerics B, Farkas R, Åkesson A (2010b) An unexpected advantage of whiteness in horses: the most horsefly-proof horse has a depolarizing white coat. Proc Roy Soc B 277:1643-1650

Horváth G, Kriska G, Malik P, Hegedüs R, Neumann L, Akesson S, Robertson B (2010c) Asphalt Surfaces as Ecological Traps for Water-Seeking Polarotactic Insects: How can the Polarized Light Pollution of Asphalt Surfaces be Reduced? Series: Environmental Remediation Technologies, Regulations and Safety. Nova Science Publishers, Inc., Hauppauge, New York, USA, p. 47, ISBN 978-1-61668-863-9

Horváth G, Móra A, Bernáth B, Kriska G (2011) Polarotaxis in non-biting midges: female chironomids are attracted to horizontally polarized light. Physiol Behav 104:1010-1015

IEA (2014) Technology Roadmap: Solar Photovoltaic Energy. International Energy Agency, Paris, France. Available online: http://www.iea.org/publications/ (Retrieved 7 October 2014)

Kagan A, Viner TC, Trail PW, Espinoza EO (2014) Avian mortality at solar energy facilities in Southern California: A preliminary analysis. National Fish and Wildlife Forensics Laboratory. U. S. Fish and Wildlife Service Report, Ashland, Oregon, USA

Kang TS, Smith AP, Taylor BE, Durstock MF (2009) Fabrication of highly-ordered $\mathrm{TiO}_{2}$ nanotube arrays and their use in dye-sensitized solar cells. Nano Lett 9:601-606

Kim J (2007) Formation of a porous silicon anti-reflection layer for a silicon solar cell. J Korean Phys Soc 50:1168-1171

Kokko H, Sutherland WJ (2001) Ecological traps in changing environments: ecological and evolutionary consequences of a behaviourally mediated Allee effect. Evol Ecol Res 3:537-351

Krcmar S (2013) Comparison of the efficiency of the olfactory and visual traps in the collection of horseflies (Diptera: Tabanidae). Entomol Gener 34:261-267 
Krcmar S, Lajos P (2011) Response of horse flies to aged equine urine (Diptera: Tabanidae). Entomol Gener 33:245-250

Kriska G, Horváth G, Andrikovics S (1998) Why do mayflies lay their eggs en masse on dry asphalt roads? Water-imitating polarized light reflected from asphalt attracts Ephemeroptera. J Exp Biol 201:2273-2286

Kriska G, Bernáth B, Horváth G (2007) Positive polarotaxis in a mayfly that never leaves the water surface: polarotactic water detection in Palingenia longicauda (Ephemeroptera). Naturwissenschaften 94:148-154

Kriska G, Malik P, Szivák I, Horváth G (2008) Glass buildings on river banks as "polarized light traps" for mass-swarming polarotactic caddis flies. Naturwissenschaften 95:461-467

Kriska G, Bernáth B, Farkas R, Horváth G (2009) Degrees of polarization of reflected light eliciting polarotaxis in dragonflies (Odonata), mayflies (Ephemeroptera) and tabanid flies (Tabanidae). J Insect Physiol 55:1167-1173

Kuo ML, Poxson DJ, Kim YS, Mont FW, Kim JK, Schubert FE, Lin SY (2008) Realization of a nearperfect antireflection coating for silicon solar energy utilization. Opt Lett 33:2527-2529

Muheim R (2011) Behavioural and physiological mechanisms of polarized light sensitivity in birds. Phil Trans Roy Soc B 366:763-771

Robertson BA, Rehage J, Sih A (2013) Ecological novelty and the emergence of evolutionary traps. Trends Ecol Evol 28:552-560

Schlaepfer MA, Runge MC, Sherman PW (2002) Ecological and evolutionary traps. Trends Ecol Evol $17: 474-480$

Schwind R (1991) Polarization vision in water insects and insects living on a moist substrate. J Comp Physiol A 169:531-540

Schwind R (1995) Spectral regions in which aquatic insects see reflected polarized light. J Comp Physiol A 177:439-448

Walston LJ, Rollins KE, Smith KP, LaGory KE, Sinclair K, Turchi C, Wendelin T, Souder H (2015) A review of avian monitoring and mitigation information at existing utility scale solar facilities. Argonne National Laboratory, U. S. Department of Energy, Argonne, IL, USA

Zar JH (2010) Biostatistical Analysis. Pearson Prentice Hall, New Jersey, USA 
Figure 1. Scanning electron microscopic picture of the upper surface and the underlying substrate of the anti-reflective matte glass pane used in the matte solar cells produced by the Danish Sunarc Ltd. and also used in our matte black test surface (photograph courtesy of Sunarc Ltd.). The pale approximately vertical lines in the picture are just scanning artefacts and bear no meaning. In the lowermost part of the picture, there are some spherical dust particles originating from the glass breakage and having no importance. 

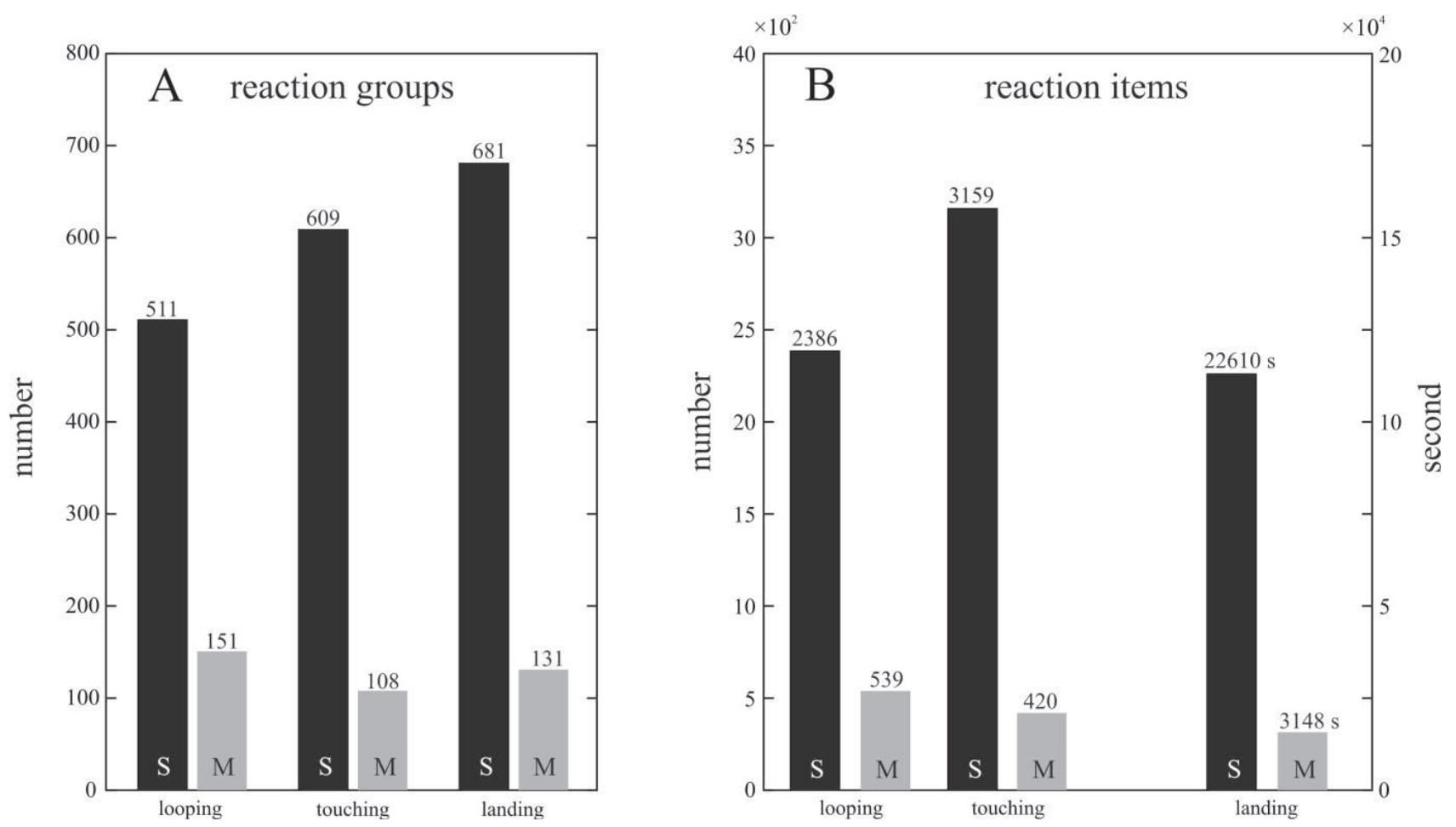

Figure 2. Number of reaction groups and number/second of reaction items of horseflies attracted to the shiny (S) and matte (M) black test surfaces used in experiment 1. In panel B the duration of landing is measured in seconds (two columns at the right side). Mann-Whitney U-tests indicate the number of reaction groups (looping: $U=24.5, Z=2.366, p=0.018$; touching: $U=21, Z=2.599, p=0.009$; landing: $U=25.0, Z=2.337, p=0.019$ ) and reaction items (looping: $U=21, Z=-2.595, p=0.0094$; touching: $U=19, Z=-2.729, p=0.0063$; landing: $U=24, Z=2.399, p=0.0164$ ) associated with shiny test surfaces were significantly higher in all cases. 


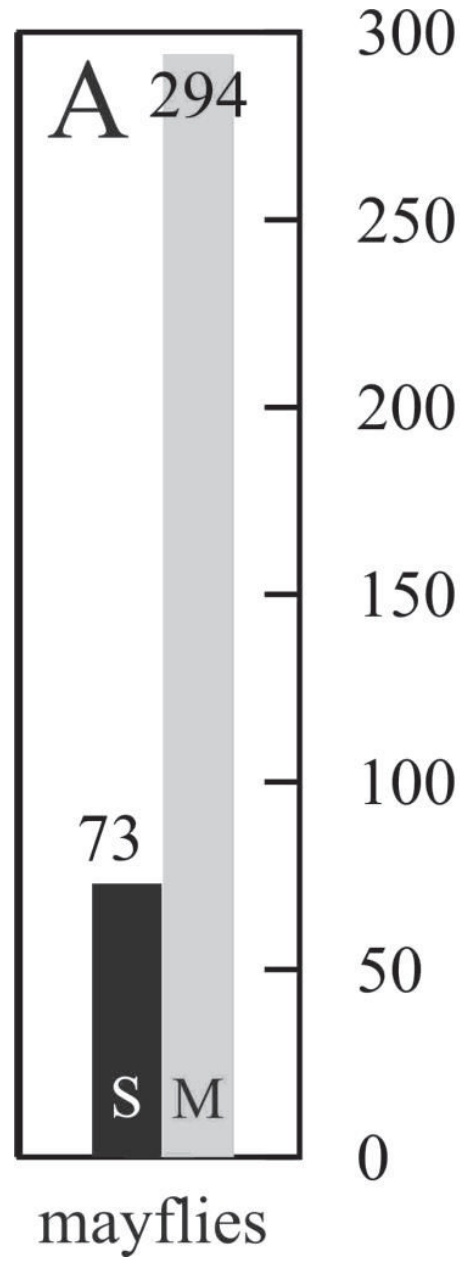

Figure 3. Number of mayflies (A) and non-biting midges (B) attracted to the shiny (S) and matte (M) black test surfaces used in experiment 2. Significantly more mayflies were attracted to the matte black surface $(\mathrm{U}=12.5, \mathrm{Z}=2.1, \mathrm{p}=0.04)$, but there was no difference in the number of non-biting midges visiting the two experimental panels $(U=27.0, Z=0.5, p=0.60)$. 

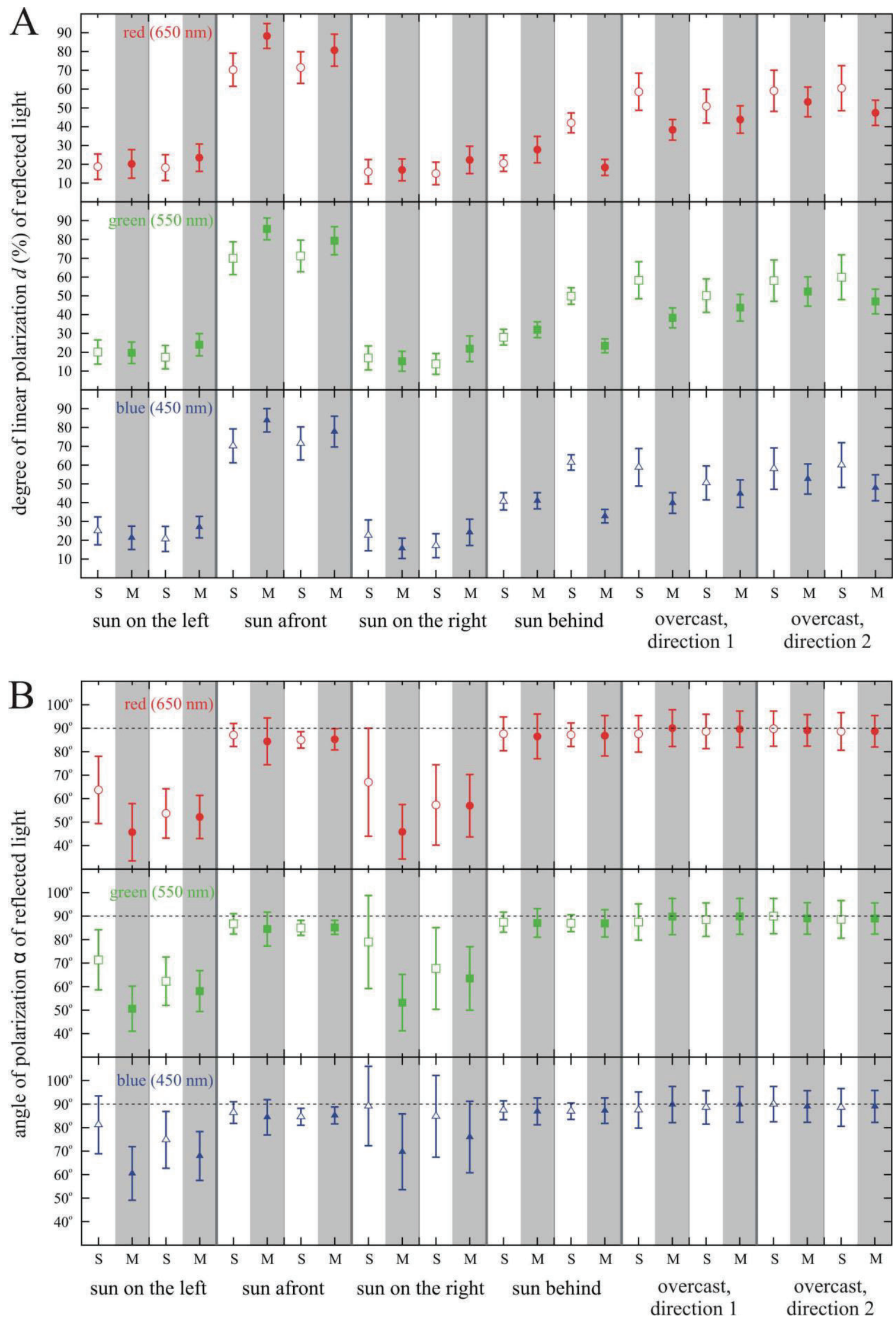
Figure 4. Means (dots, rectangles, triangles) and standard deviations (vertical I-s) of the degree of linear polarization $d(\%, \mathrm{~A})$ and the angle of polarization $\alpha\left({ }^{\circ}, \mathrm{B}\right.$, measured clockwise from the vertical) of light reflected from the shiny ( $\mathrm{S}$, empty dots, rectangles and triangles, white columns) and matte (M, filled dots, rectangles and triangles, grey columns) horizontal black test surfaces used in our field experiments measured by imaging polarimetry in the red $(650 \mathrm{~nm})$, green $(550 \mathrm{~nm})$ and blue $(450 \mathrm{~nm})$ spectral ranges from different directions of view relative to the solar meridian (SM) under a clear and overcast sky. Sun on the left: the sun shone from the left, perpendicular to SM. Sun afront: the sun shone from afront. Sun on the right: the sun shone from the right, perpendicular to SM. Sun behind: the sun shone from behind. Direction 1: arbitrary relative to SM. Direction 2: perpendicular to direction 1. In $B$ the horizontal dashed lines represent horizontal polarization $\left(\alpha=90^{\circ}\right.$ from the vertical). The numerical values of the data displayed here are in Supporting Table S1. 


\section{Polarized light pollution of matte solar panels}
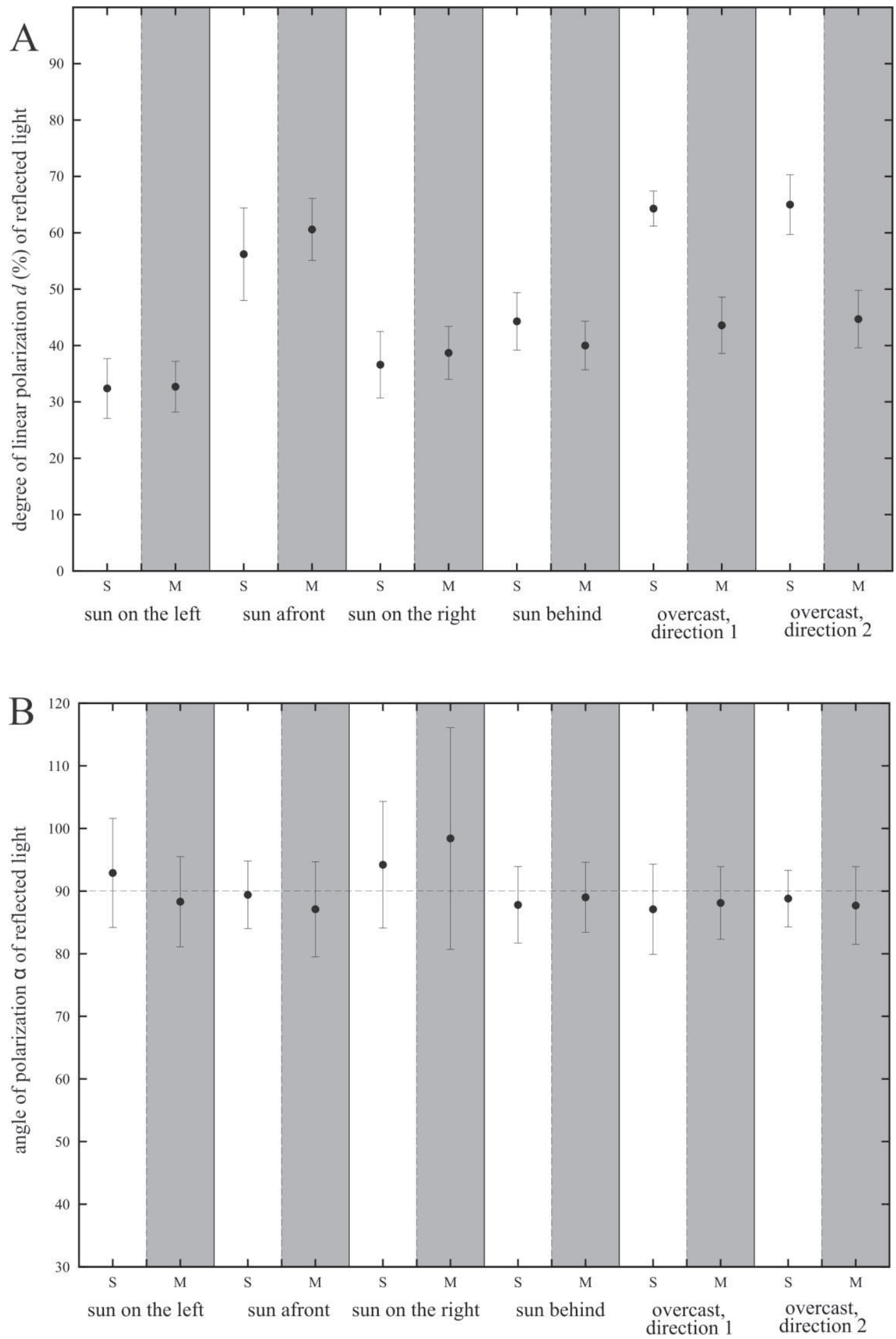

Figure 5. As Fig. 4 for the ultraviolet $(350 \mathrm{~nm})$ spectral range. The numerical values of the data displayed here are in Supporting Table S2. 
sunlit shiny solar panel
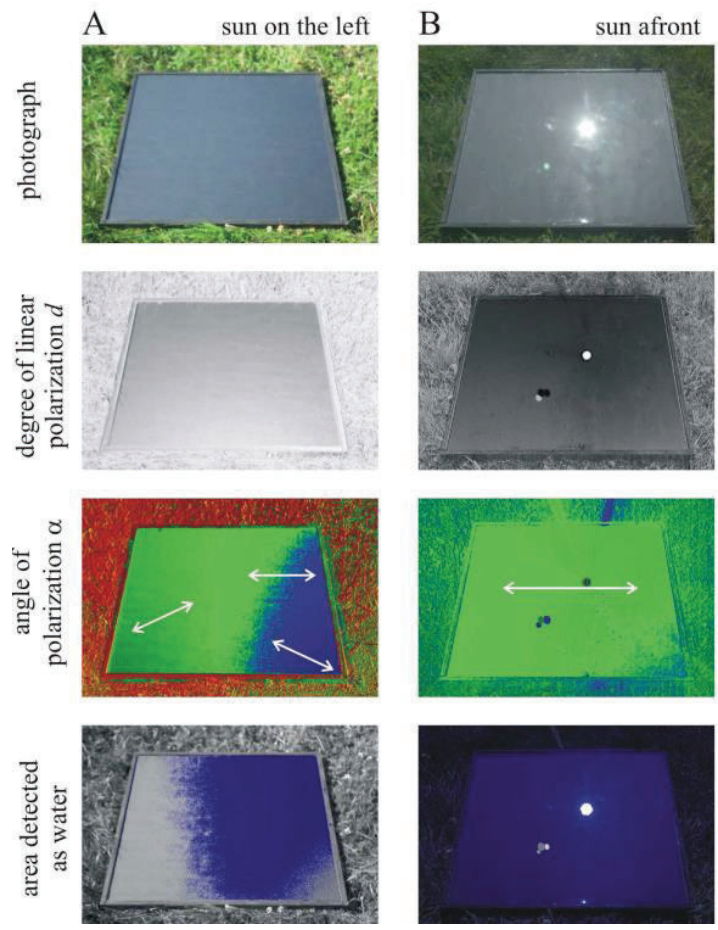
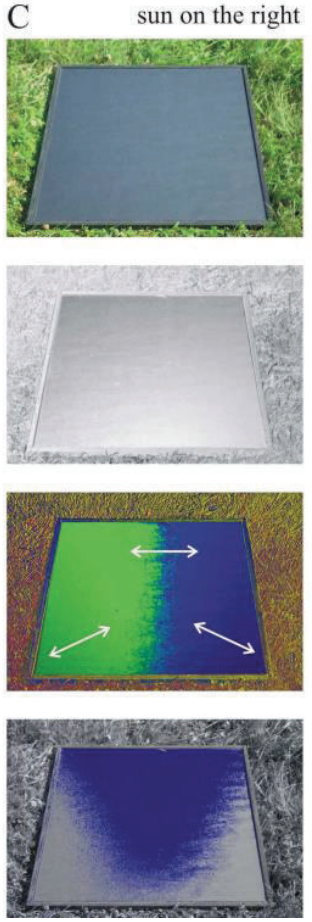
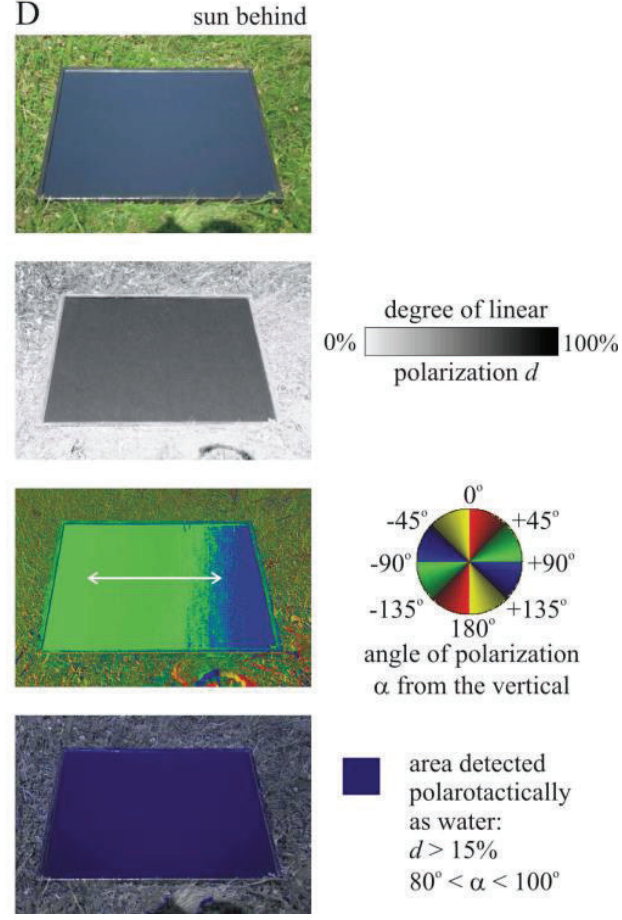

area detected polarotactically as water: $d>15 \%$ $80^{\circ}<\alpha<100^{\circ}$

Figure 6. Photograph, and patterns of the degree of linear polarization $d$, the angle of polarization $\alpha$ (measured clockwise from the vertical) and the area detected polarotactically as water (for which $d>$ $15 \%$ and $80^{\circ}<\alpha<100^{\circ}$ ) for one of the two shiny black test panels used in our field experiments. $d$ and $\alpha$ were measured by imaging polarimetry in the green $(550 \mathrm{~nm})$ spectral range under a clear sky for four different directions of view relative to the solar meridian SM, including: (A) The sun shone from the left, perpendicular to SM. (B) The sun shone from afront. (C) The sun shone from the right, perpendicular to SM. (D) The sun shone from behind. See the original colour version of this figure in the online version of this paper. 
sunlit matte solar panel
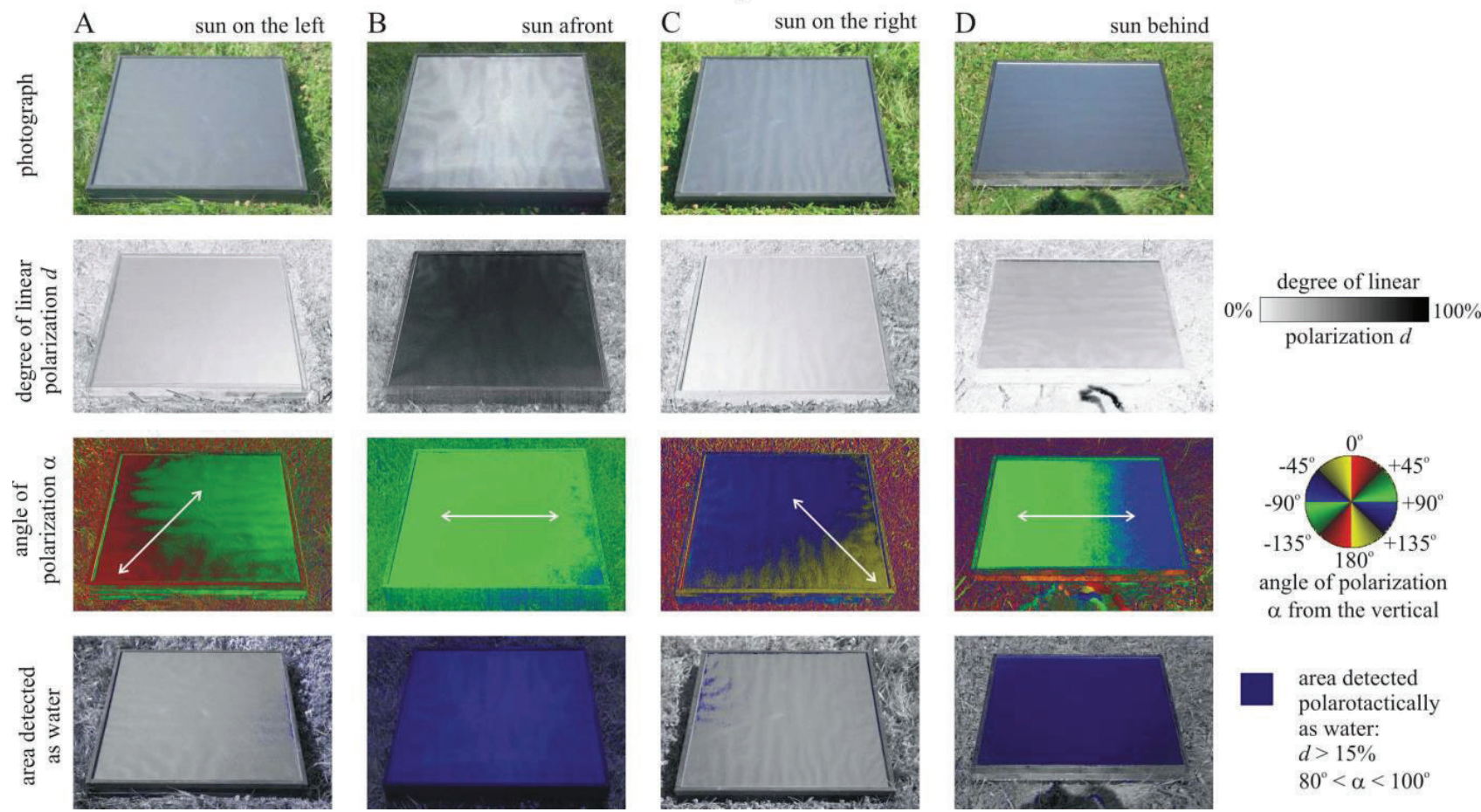

Figure 7. As Fig. 6 for one of the two matte black test panels used in our field experiments. See the original colour version of this figure in the online version of this paper. 
shiny and matte solar panels under an overcast sky
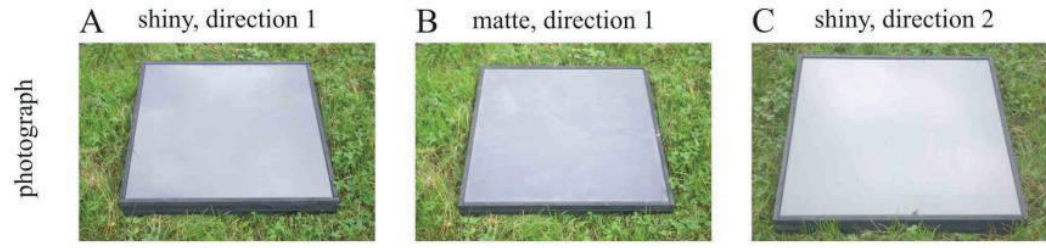

D matte, direction 2
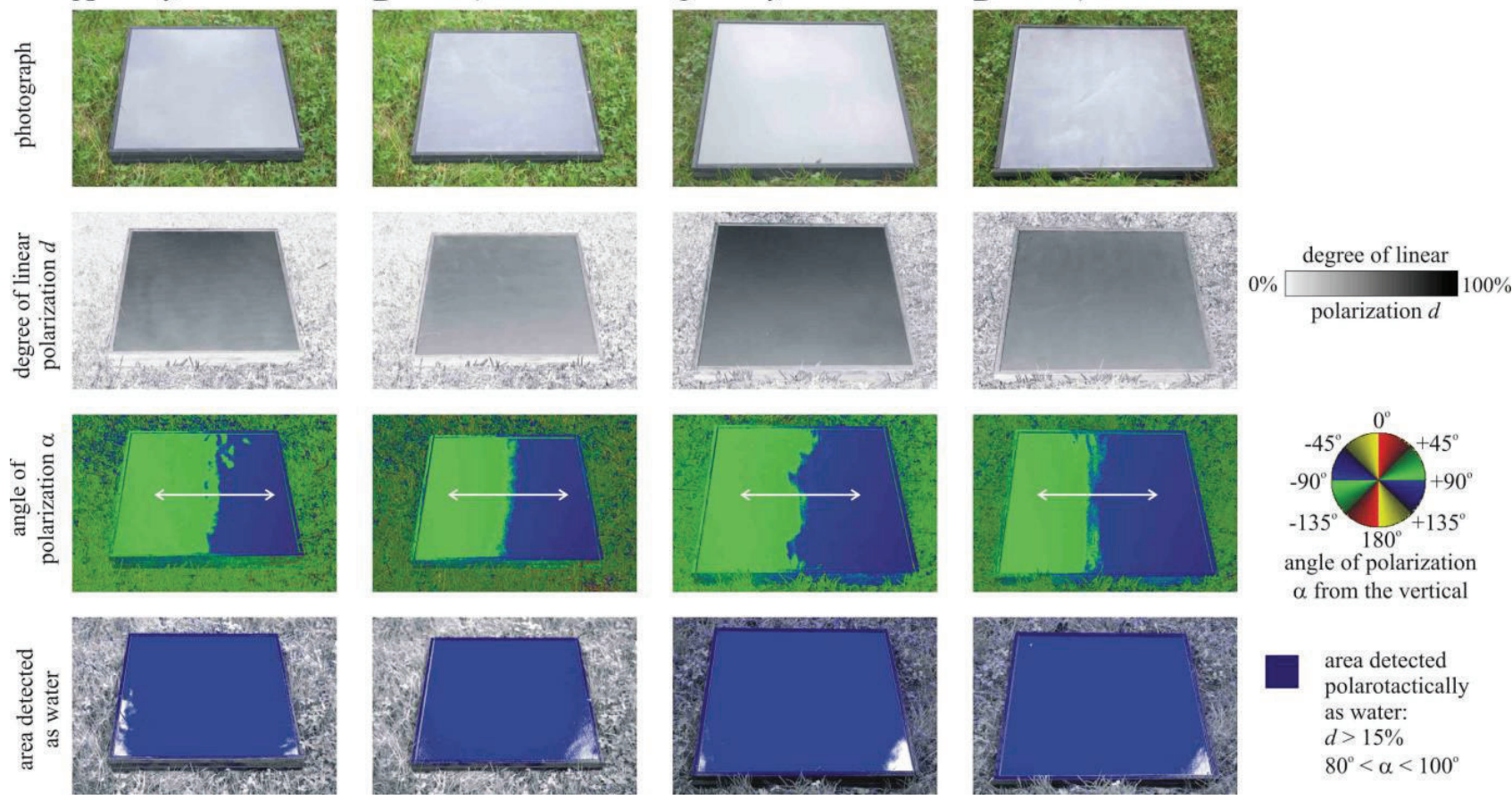

Figure 8. As Fig. 6 for one of the two shiny $(A, C)$ and matte $(B, D)$ black test panels used in our field experiments under an overcast sky from horizontal directions of view 1 (A, B) and 2 (C, D), which were perpendicular to each other and direction 1 was arbitrary. See the original colour version of this figure in the online version of this paper. 